\title{
In-situ $\mathrm{Pb}^{2+}$ remediation using nano iron particles
}

\author{
Mohammad Reza Fadaei Tehrani ${ }^{1 *}$, Abolfazl Shamsai ${ }^{1}$ and Manoochehr Vossughi ${ }^{2}$
}

\begin{abstract}
Originally, application of nano zero valent iron ( $\mathrm{nZVI}$ ) particles for the removal of lead $\left(\mathrm{Pb}^{2+}\right)$ in porous media was studied. At first, stabilized nZVI (S-nZVI) was prepared and characterized, then used in batch and continuous systems. Based on the batch experiments, corresponding reaction kinetics well fitted with the pseudo-first-order adsorption model, and reaction rate ranged from 0.01 to $0.04 \mathrm{~g} / \mathrm{mg} / \mathrm{min}$ depend on solution $\mathrm{pH}$ and the molar ratio between Fe and $\mathrm{Pb}$. In batch tests, optimal condition with more than $90 \%$ removal efficiency at 60 min was observed at a pH range of 4 to 6 and Fe/Pb ratio more than 2.5. Continuous experiments exposed that $\mathrm{Pb}^{2+}$ remediation was as well influenced by seepage velocity, grain size, and type of porous media. The maximum $\mathrm{Pb}^{2+}$ removal efficiency in batch and bench-scale systems were $97 \%$ and $81 \%$, correspondingly. The results have shown the ability of S-nZVI to use in permeable reactive barriers, as an efficient adsorbent for $\mathrm{Pb}^{2+}$, because of its excellent stability, high reducing power, and a large surface area.
\end{abstract}

Keywords: nZVI, in-situ, Remediation, Lead, Bench-scale

\section{Background}

During the last two decades, presence of heavy metal ions in the environment, especially in water sources, was becoming a major concern due to their non-biodegradability, toxicity, wide-spread presence, and tendency to accumulate in living organisms [1]. Lead, a main concern metal pollutant, is widely used in battery manufacturing, electroplating industry, painting and printing processes, plumbing and the combustion of automobile petrol [2]. The U.S. Environmental Protection Agency (U.S.EPA) has set a permissible limit of $0.015 \mathrm{mg} / \mathrm{L}$ in drinking water and has placed it on top of the priority list of toxic pollutants [3]. Lead pollution can cause nervous system damage, renal kidney disease, mental retardation, cancer, and anemia in humans [2]. Chemical reduction, ion exchange, chemical precipitation, mineral adsorption, membrane separation, and bio-sorption are the most frequently used treatment technologies for $\mathrm{Pb}^{2+}$ removal [4] which are ex-situ techniques. Most of these methods are only suitable for the removal of $\mathrm{Pb}^{2+}$ in low concentrations and often require extensive processing as well as being too expensive.

Recently, in-situ techniques such as permeable reactive barriers (PRB) have become promising alternatives to ex-situ methods owing to their lower operating costs [5]. Nano zero valent iron particles could be used as reducing agents in PRBs for removing the wide range of pollutions that promises to be significantly more effective than granular iron, the reaction rates are 25 to 30 times faster, and the sorption capacity is much higher compared with granular iron [2].

The high reactivity of nZVI is the consequence of greater total surface area, higher density of reactive sites on the particle surface, and/or more intrinsic reactivity of the surface sites [6]. Iron nano particles have been extensively studied to remediate pollutants such as chlorinated compounds and metal ions [7], nitrate [8], carbon tetrachloride, benzoquinone [9], metalloids such as arsenic [10], and organic compounds [11]. However, there are many uncertainties regarding to the features of nZVIbased remediation technologies, which have made it difficult to engineer applications for optimal performance or to assess the risk to human or ecological health. In this study, application of surface modified nZVI (S-nZVI) for $\mathrm{Pb}^{2+}$ remediation in porous media was experimented that consists of following steps: (1) synthesis, stabilization, and characterization of S-nZVI; (2) determination of kinetics of $\mathrm{Pb}^{2+}$ removal by $\mathrm{nZVI}$ and the key factors affecting the reaction; (3) investigation of the effects of flow characteristics on the removal rate; (4) bench-scale modeling of lead remediation under natural conditions.

\footnotetext{
* Correspondence: fadaei@mehr.sharif.edu

${ }^{1}$ Department of Civil Engineering, Sharif University of Technology, Tehran, Iran

Full list of author information is available at the end of the article
}

() Biomed Central 


\section{Methods}

\section{Materials}

Lead nitrate $\left(\mathrm{Pb}\left(\mathrm{NO}_{3}\right)_{2}\right)$, used as the source of $\mathrm{Pb}^{2+}$ in all experiments, and other chemical reagents, including $\mathrm{FeCl}_{3} \cdot 6 \mathrm{H}_{2} \mathrm{O}, \mathrm{NaBH}_{4}$, and $\mathrm{NiCl}_{2} \cdot 6 \mathrm{H}_{2} \mathrm{O}$, were supplied by Merck, Germany. The concentration of lead, divalent and total, was determined using an atomic absorption spectrometer (Varian SpectrAA 220, Germany).

\section{NZVI preparation}

The iron nano particles were prepared on-site to prevent more oxidation of nZVI surface. To synthesize the nZVI particles, $0.15 \mathrm{M} \mathrm{NaBH}_{4}$ solution was added slowly with the rate of 1 to $2 \mathrm{~mL} / \mathrm{min}$ into $0.1 \mathrm{M} \mathrm{FeCl}_{3} \cdot 6 \mathrm{H}_{2} \mathrm{O}$ aqueous solution at ambient temperature and vigorously stirred at $400 \mathrm{rpm}$ [12]. During this reaction, ferric ions were reduced into black particles by sodium borohydride as the reductant, according to the following reaction [13]:

$$
\begin{gathered}
4 \mathrm{Fe}^{3+}{ }_{(\mathrm{aq})}+3 \mathrm{BH}_{4}+9 \mathrm{H}_{2} \mathrm{O} \rightarrow 4 \mathrm{Fe}^{\mathrm{o}}{ }_{(\mathrm{s})} \downarrow \\
+3 \mathrm{H}_{2} \mathrm{BO}_{3}+12 \mathrm{H}^{+}{ }_{(\mathrm{aq})}+6 \mathrm{H}_{2(\mathrm{~g})} \uparrow
\end{gathered}
$$

The black precipitates were filtered by vacuum filtration through $0.45 \mu \mathrm{m}$ filter papers and then washed with DI water and ethanol three times.

\section{NZVI stabilization}

Previous researches have indicated that nZVI particles aggregate quickly, after decreasing surface area for reaction and limiting mobility. To control nano particle agglomeration, various particle stabilizing strategies have been reported that surface modification with surfactant is one of the most important approaches [14]. Surfactants, such as starch, could be coated on existing nZVI particles in a post-synthesis process; or synthesizing nZVI in the presence of polymer in a pre-synthesis process. The post-synthesis stabilization approach has been shown to decrease reactivity whereas the presynthesis approach has improved reactivity and significantly increased surface area [15]. In the present study, nZVI was stabilized by starch in a pre-synthesis process, according to He and Zhao method [16], which is termed here as S-nZVI.

\section{Batch experiments}

The batch experiments were conducted to find the finest condition for columns tests. In addition, useful information could be obtained about the effect of some key parameters. As listed in Table 1, the effects of several main variables were investigated in batch tests, one parameter changed while others were kept constant. Batch experiments were carried out in sealed flasks at $20^{\circ} \mathrm{C}$. Predefined S-nZVI and $125 \mathrm{~mL}$ buffered $\mathrm{Pb}^{2+}$ solution with initial concentration of $200 \mathrm{mg} / \mathrm{L}$ and $\mathrm{pH} 4.0$ were added to each flask, and the suspension was stirred. Aliquots of the samples were taken at certain time intervals and analyzed immediately following paper filtration. All experiments were conducted in duplicate and the results were averaged.

\section{Continuous experiments}

Continuous experiments were performed in two configurations:

1 - Transparent column with $55 \mathrm{~mm}$ diameter and $650 \mathrm{~mm}$ length filled with glass beads (Figure 1);

2 - bench-scale apparatus consisted of two PVC columns with $300 \mathrm{~mm}$ diameter and $1250 \mathrm{~mm}$ height filled with packed sand (Figure 2).

Prior to each run, in the first system, glass beads were soaked in hydrogen peroxide solution for $10 \mathrm{hr}$, washed with de-ionized water, and finally baked at $105^{\circ} \mathrm{C}$ for $24 \mathrm{hr}$ [17]. For the continuous system, sands were prepared by baking at $500^{\circ} \mathrm{C}$ for $24 \mathrm{hr}$ to eliminate adsorbed organic matter. In this set of experiments, the $\mathrm{pH}$ of the solution was adjusted to $4 \pm 0.2$ using $0.1 \mathrm{~N} \mathrm{HCl}$.

The effects of some flow parameters were investigated by transparent column model, including seepage velocity and S-nZVI loading. Seepage velocity tests, consisted of $5,10,20$, and $40 \mathrm{~m} / \mathrm{d}$, were conducted by distilled water with initial $\mathrm{Pb}^{2+}$ concentrations of $200 \mathrm{mg} / \mathrm{L}$, and $5 \mathrm{~g}$ S-nZVI injection. S-nZVI loading tests were experimented by initial $\mathrm{Pb}^{2+}$ concentrations of $200 \mathrm{mg} / \mathrm{L}$, seepage velocity of $10 \mathrm{~m} / \mathrm{d}$, and frequent 5,10 , and $15 \mathrm{~g} \mathrm{~S}-\mathrm{nZVI}$ injection.

\begin{tabular}{|c|c|c|c|c|c|c|c|c|c|}
\hline \multicolumn{3}{|l|}{ Experimental set } & \multicolumn{6}{|l|}{ Variable parameter } & \multirow{2}{*}{$\begin{array}{l}\text { Controlled conditions } \\
\text { S-nZVl: } 0.5 \mathrm{~g} / \mathrm{L}, \mathrm{C}_{\mathrm{o}}: 200 \mathrm{mg} / \mathrm{L}\end{array}$} \\
\hline Batch & & $1-1$ & Controlled pH & 2.0 & 4.0 & 6.0 & 8.0 & & \\
\hline & & $1-2$ & Initial $\mathrm{Pb}^{2+}$ (mg/L) & 100 & 200 & 400 & 800 & & S-nZVI: 0.5 g/L, pH: 4.0 \\
\hline & & $1-3$ & S-nZVI con.(g/L) & 0.1 & 0.2 & 0.5 & 1.0 & 2.0 & $\mathrm{C}_{\mathrm{o}}: 200 \mathrm{mg} / \mathrm{L}, \mathrm{pH}: 4.0$ \\
\hline \multirow[t]{3}{*}{ continuous experiments } & Transparent column & $2-1$ & Seepage velocity $(\mathrm{m} / \mathrm{d})$ & 5 & 10 & 20 & 40 & & $\begin{array}{l}\mathrm{C}_{\mathrm{o}}=200 \mathrm{mg} / \mathrm{L}, \mathrm{pH}: 4, \\
\text { Seepage velocity: } 10 \mathrm{~m} / \mathrm{d}\end{array}$ \\
\hline & & $2-2$ & S-nZVI loading (g) & 1 & 2 & 5 & 10 & & $\mathrm{nZVI}: 5 \mathrm{~g}, \mathrm{pH}: 4, \mathrm{C}_{\mathrm{o}}=200 \mathrm{mg} / \mathrm{L}$ \\
\hline & Bench-scale & $3-1$ & Seepage velocity $(\mathrm{m} / \mathrm{d})$ & 10 & 20 & 40 & & & $\mathrm{nZVI}: 15 \mathrm{~g}, \mathrm{pH}: 4, \mathrm{C}_{\mathrm{o}}=200 \mathrm{mg} / \mathrm{L}$ \\
\hline
\end{tabular}

Table 1 Experimental design in present study* all experiments were conducted in ambient temperature $15-20^{\circ} \mathrm{C}$ 


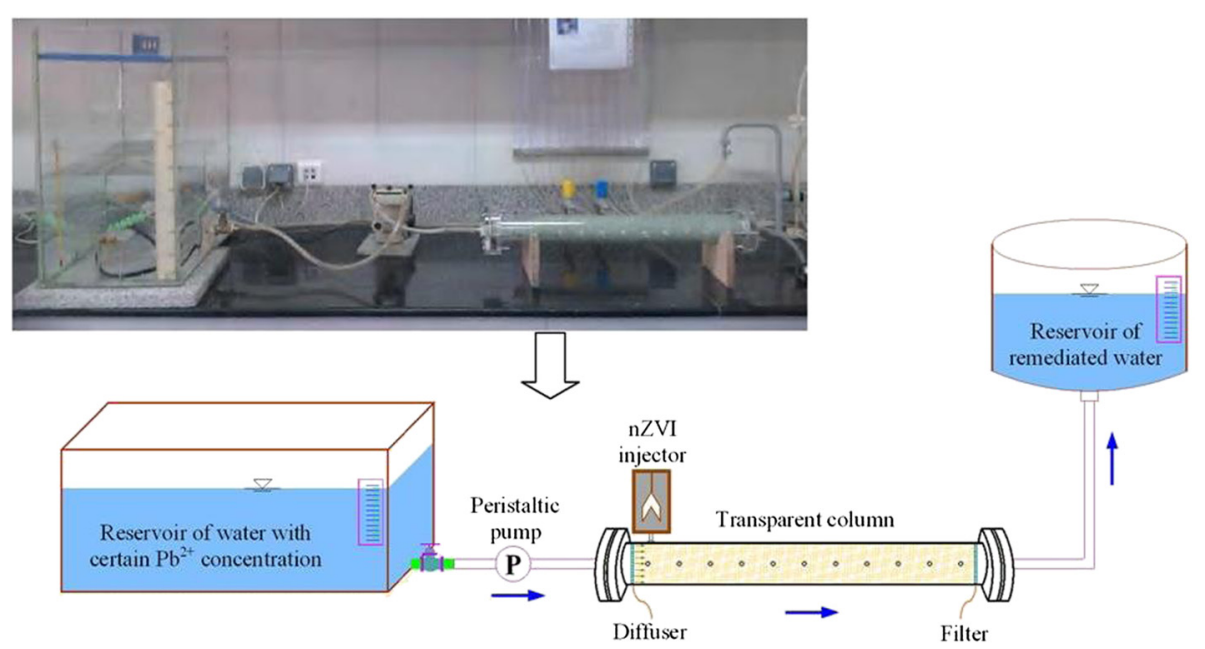

Figure 1 Picture and schematic of transparent column model filled with glass beads.

The bench-scale experiments were planned based on the results of the batch and transparent column tests. The S-nZVI injected into the bottom center of the column forms a permeable reactive zone which reduced inlet $\mathrm{pb}^{2+}$. This configuration is applicable to study the effects of groundwater ionic strength, porous media type, seepage velocity, initial concentration of $\mathrm{pb}^{2+}$ and nano particle loading, at the same time. Three treatments, consisted of 5, 10, and $15 \mathrm{~g}$ initial S-nZVI loading, were carried out in the bench-scale model. Other conditions were kept as seepage velocity $10 \mathrm{~m} / \mathrm{d}, \mathrm{pH} 4$, and were used wastewater with initial $\mathrm{Pb}^{2+}$ concentration of $200 \mathrm{mg} / \mathrm{L}$.

\section{Results and discussion \\ Characteristics of S-nZVI}

To characterize the stabilized iron nano particles, X-ray powder diffraction (XRD), scanning electron microscopy (SEM), and dynamic light scattering (DLS) were recorded as the results shown in Figure 3. The starched nZVI particles displayed much less agglomeration than those prepared without a stabilizer while S-nZVI remained suspended in water for several hours, non-starched particles agglomerated and precipitated within minutes. XRD results, obtained by a D8 Advanced Bruker diffractometer, indicated the presence of $\mathrm{Fe}^{\circ}$ (peaked at $2 \theta=42,67,82$ ), and $\mathrm{Fe}_{2} \mathrm{O}_{3}(2 \theta=35,53)$. SEM analyses, by a S4160 FESEM device, denoted that the S-nZVI were present as discrete particles as opposed to dendritic flocs for nonstarched particles. DLS was performed using a S-red Badge model ZEN1600. The mean particle size was estimated to be $78 \mathrm{~nm}$ with a standard deviation of $14 \mathrm{~nm}$, which translated to a surface area of at least $25 \mathrm{~m}^{2} / \mathrm{g}$.

\section{Batch experiments}

\section{a. Effect of solution $\mathbf{p H}$}

Generally, $\mathrm{pH}$ of solution is an important factor for heavy metal ions removal by nZVI. It is widely accepted that low $\mathrm{pH}$ has a negative effect on metal adsorption by nZVI [18]. When $\mathrm{pH}$ is lower than zero point charge $\left(\mathrm{pH}_{\mathrm{zpc}}\right)$, the positive charge surface of nZVI will repulse

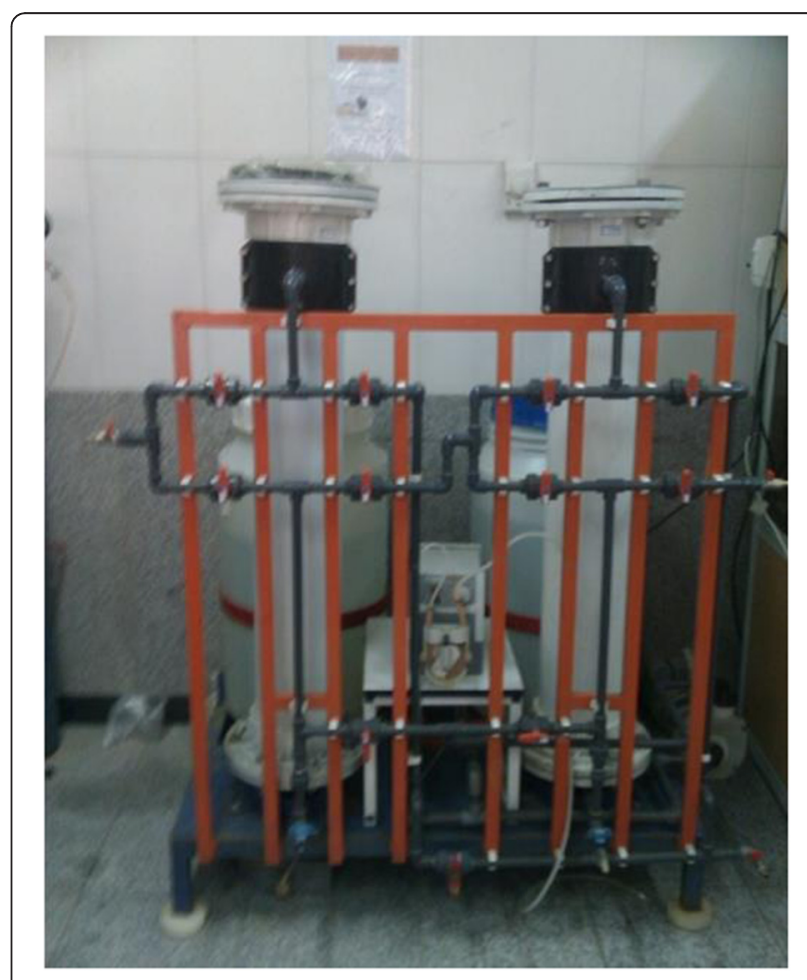

Figure 2 Picture of bench-scale model. 


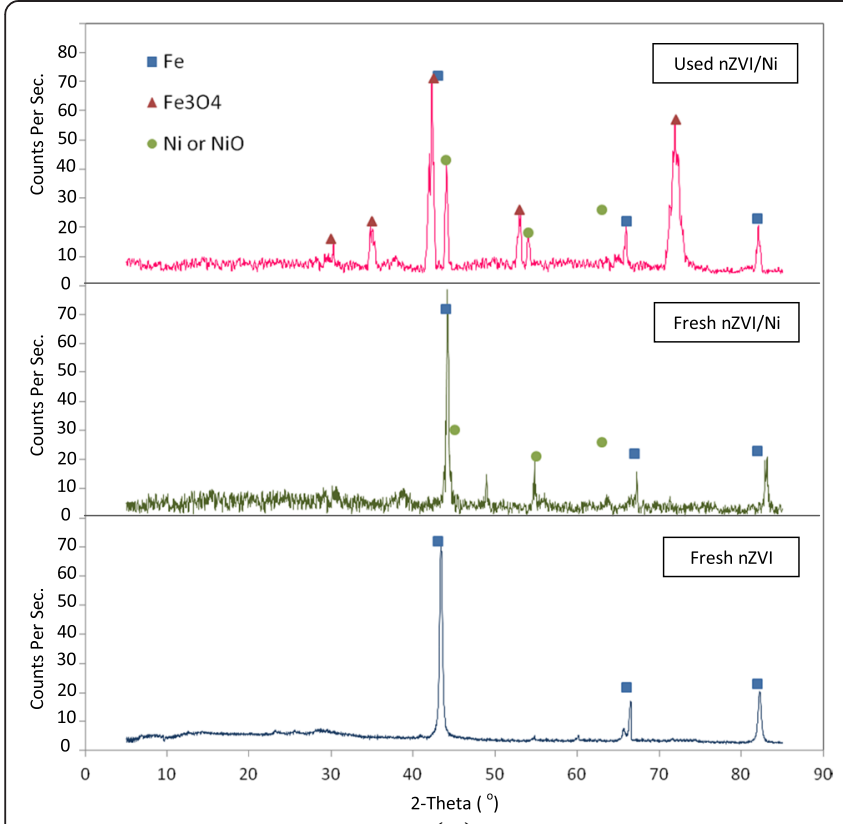

(a)

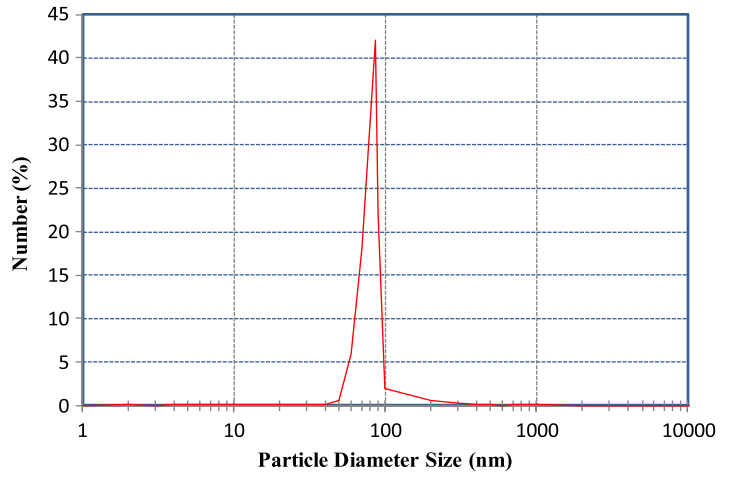

(c)

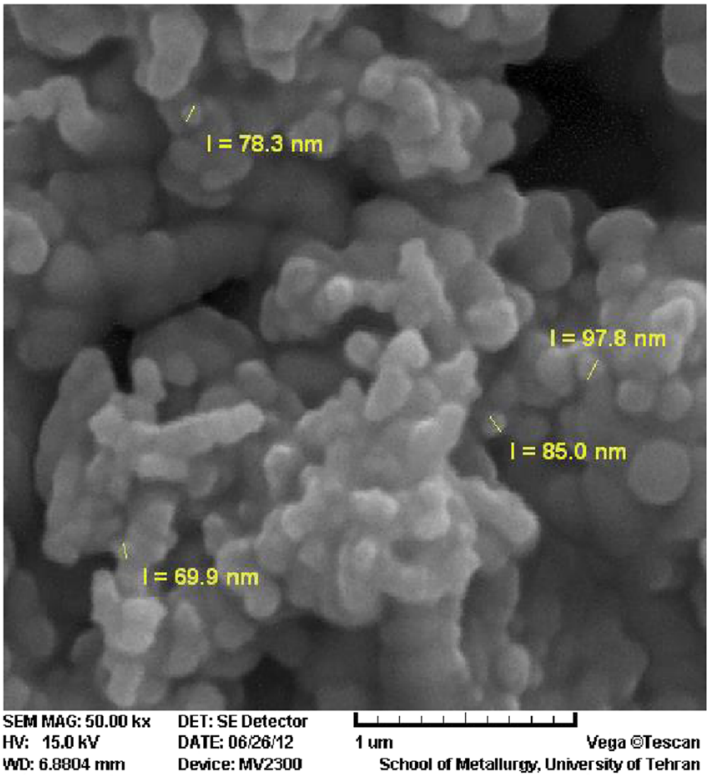

(b)
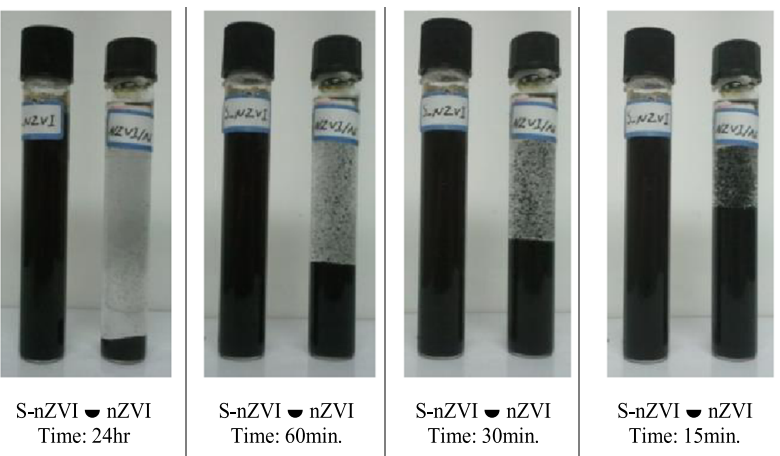

(d)

Figure 3 Characteristic of synthesized nZVI, (a) XRD diagram, (b) SEM image, (c) DLS results, (d) stabilization status.

metal cations, and results lower removal efficiency [19]. On the other hand, it is found out from equation 2 that $\mathrm{H}^{+}$is strongly produced along the $\mathrm{Pb}^{2+}$ reduction reaction that point to an alkaline environment is preferred by the $\mathrm{Pb}^{2+}$ removal in aqueous solution [20].

$$
2 \mathrm{Fe}^{\mathrm{o}}+3 \mathrm{~Pb}^{2+}+4 \mathrm{H}_{2} \mathrm{O} \rightarrow 2 \mathrm{FeOH}+3 \mathrm{~Pb}^{\circ}+2 \mathrm{H}^{+}
$$

Figure 4a presents the results of batch experiments in which S-nZVI are exposed to $\mathrm{Pb}^{2+}$ buffered solution with different $\mathrm{pH}$ values. At $\mathrm{pH}<4.0$ or $>6.0$ after $60 \mathrm{~min}$, less than $60 \%$ of $\mathrm{Pb}^{2+}$ was degraded, while more than $80 \%$ removal efficiency was obtained after $60 \mathrm{~min}$ at pH $5 \pm 1$. The results suggest that rapid reduction of $\mathrm{Pb}^{2+}$ into $\mathrm{Pb}^{\circ}$ occurs while $\mathrm{pH}<6$, and adsorption was optimized by adjusting the $\mathrm{pH}>4$. Thus, it can be concluded that $\mathrm{pH}$ around 5 favors for $\mathrm{Pb}^{2+}$ removal by nZVI.

\section{b. Effect of initial $\mathbf{P b}^{2+}$ concentration}

As shown in Figure $4 \mathrm{~b}$, the effect of initial concentration of $\mathrm{Pb}^{2+}$ on removal efficiency was investigated in the range of 100 to $800 \mathrm{mg} / \mathrm{L}$. The equilibrium time became longer and the final removal efficiency of $\mathrm{Pb}^{2+}$ decreased as the initial $\mathrm{Pb}^{2+}$ concentration increased; So, the percentage of $\mathrm{Pb}^{2+}$ removed within $60 \mathrm{~min}$ at an initial concentration of $100 \mathrm{mg} / \mathrm{L}$ was nearly $85 \%$, and it was only $58 \%$ at an initial concentration of $800 \mathrm{mg} / \mathrm{L}$. Furthermore, as revealed in Figure 5b, the plot well fitted to the pseudo first order adsorption model, where 


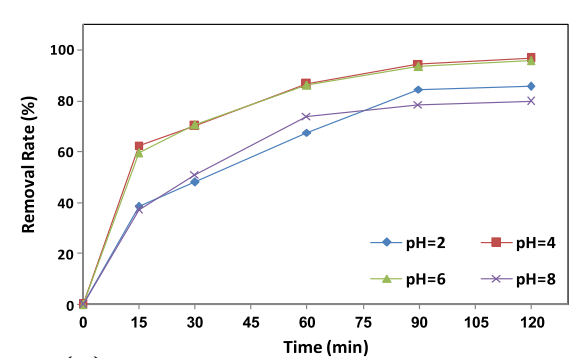

(a) Batch Experiments: effect of solution $\mathrm{pH}$ on the removal rate

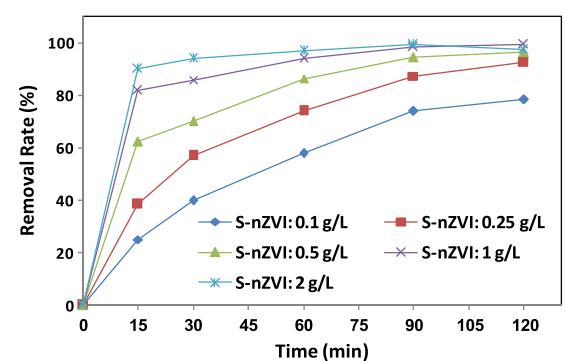

(c) Batch Experiments: effect of S-nZVI dosage on the removal rate

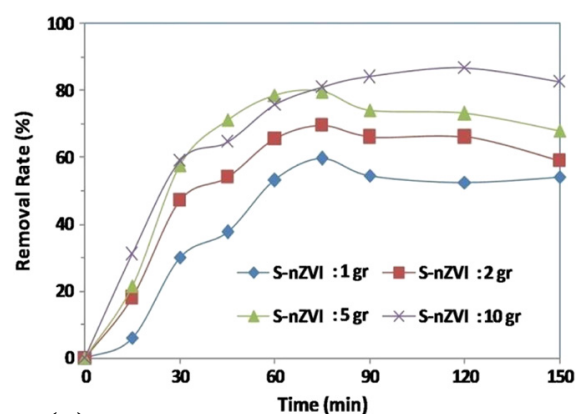

(e) Column experiments: effect of S-nZVI loading on the removal rate

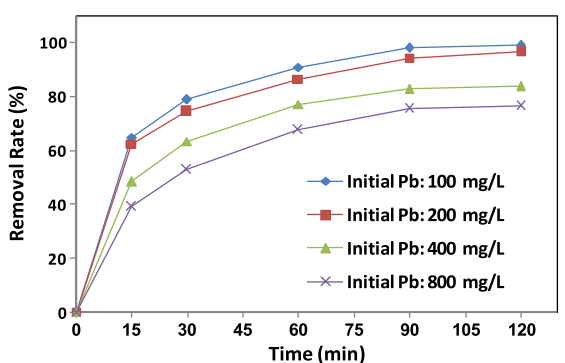

(b) Batch Experiments: effect of initial $\mathrm{Pb}^{2+}$ concentrations on the removal rate

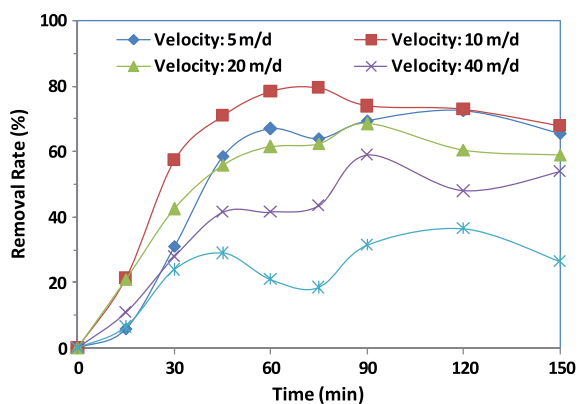

(d) Column experiments: effect of seepage velocity on the removal rate

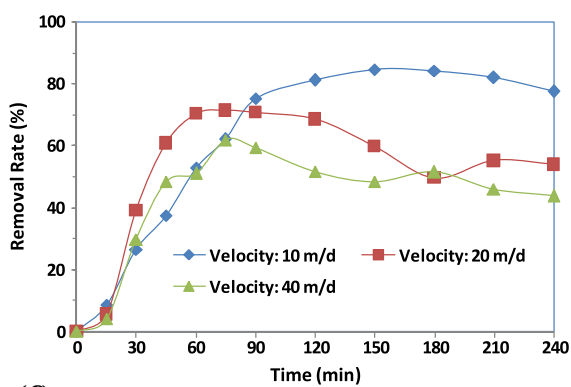

(f) Bench-scale experiments: effect of seepage velocity on the removal rate

Figure 4 Results of $\mathrm{Pb}^{2+}$ removal by experiments in batch, column and bench-scale models.

the observed rate constant decreased significantly as the initial $\mathrm{Pb}^{2+}$ concentration increased. Generally, when nZVI concentration was constant, the lower efficiency and slower rate of $\mathrm{Pb}^{2+}$ removal were found at higher initial concentrations of $\mathrm{Pb}^{2+}$. These results suggest that the capacity of the S-nZVI for lead removal is about $430 \mathrm{mg} \mathrm{Pb} / \mathrm{g}$ S-nZVI.

\section{c. Effect of S-nZVI concentration}

As shown in Figure $4 \mathrm{c}$, the $\mathrm{Pb}^{2+}$ removal efficiency improved as the S-nZVI concentration increased. The removal efficiency of $\mathrm{Pb}^{2+}$ was about $50 \%$ using S-nZVI at $0.1 \mathrm{~g} / \mathrm{L}$ for $60 \mathrm{~min}$, but was nearly $95 \%$ when the S-nZVI concentration was higher than $1 \mathrm{~g} / \mathrm{L}$. In the same conditions, $\mathrm{K}_{\mathrm{obs}}$ raised as the S-nZVI concentration increased.
These phenomena can be attributed to the increase in available active sites resulting from the increase in S-nZVI concentration, where the lead reduction occurred. Additionally, lead ions removal sharply enhanced by increasing contact time for the first $60 \mathrm{~min}$, and then gradually approached equilibrium after approximately 120 min.

\section{d. Kinetics of the $\mathrm{Pb}^{2+}$ reduction}

The adsorption kinetics of $\mathrm{Pb}^{2+}$ ions was studied to determine the required time to achieve equilibrium adsorption of lead ions on the adsorbents. It was reported that nZVI can remove metal ions from aqueous solutions by various mechanisms, including electrostatic adsorption, complex formation, reduction, and 


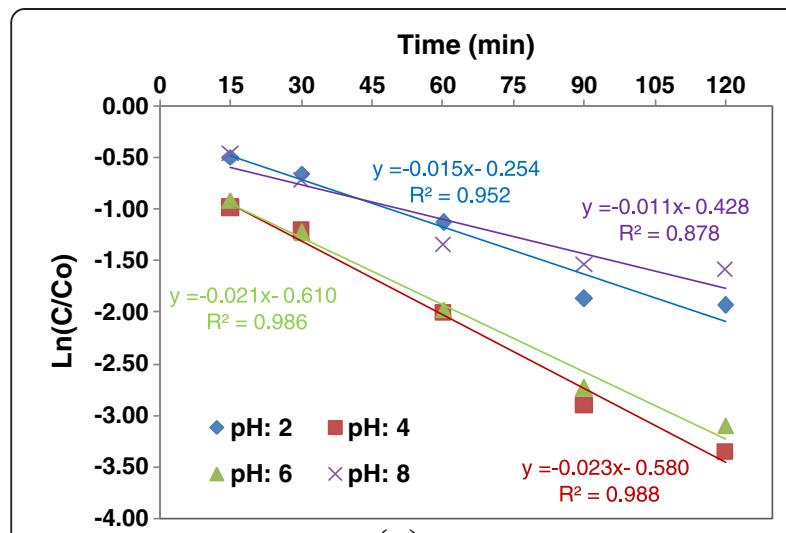

(a) solution $\mathrm{pH}$

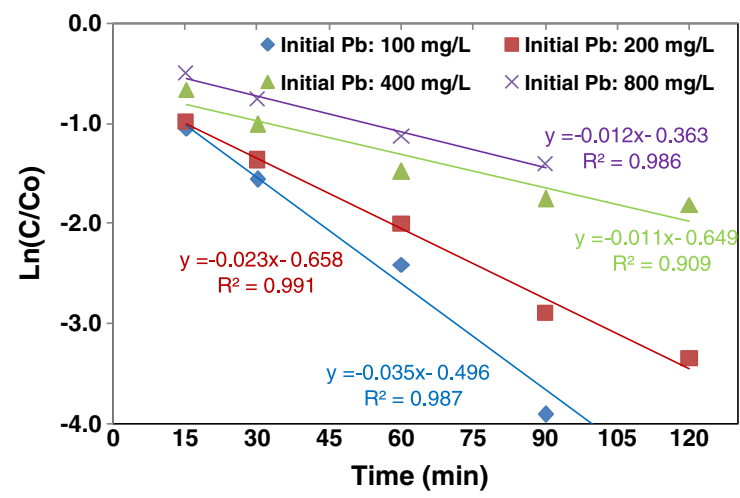

(b) $\mathrm{Pb}^{2+}$ concentrations

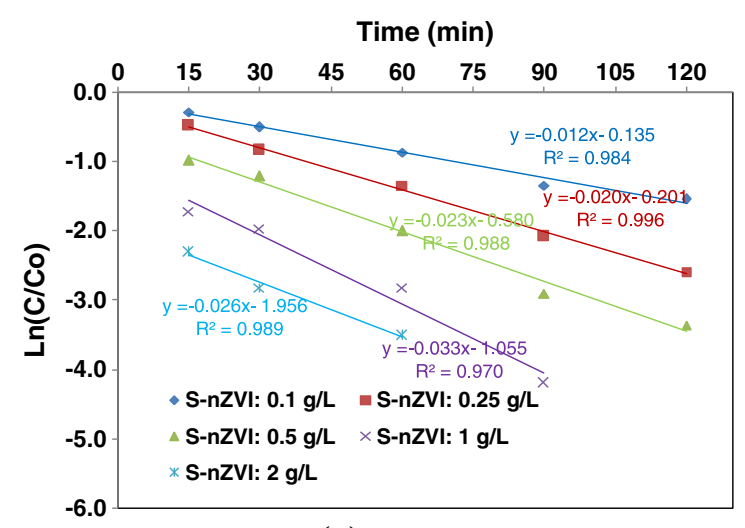

(c) S-nZVI dosage

Figure 5 Pseudo first-order adsorption kinetic plots (corresponding to Figure $4 a, b$ and c, respectively).

precipitation [21]. It seems that when nZVI was used, the nano particles captured aqueous lead ions easily and rapidly because of their large surface areas and high reactivity.

In this research, the kinetics was investigated experimentally under different values of initial $\mathrm{Pb}^{2+}$ concentration, solution $\mathrm{pH}$, and S-nZVI dosage by using pseudo first-order reaction model that can be represented as following:

$$
\ln \left(C / C_{o}\right)=-K_{\text {obs }} t
$$

where $C_{o}$ and $C$ are the concentration of $\mathrm{Pb}^{2+}(\mathrm{mg} / \mathrm{g})$ at initial and time $t(\mathrm{~min})$, respectively. $K_{o b s}\left(\mathrm{~min}^{-1}\right)$ is the equilibrium rate constant for first order adsorption. Therefore, by plotting $\ln \left(C / C_{o}\right)$ against $t$, the values of $K_{o b s}$ can be found from the slope of the revealed plots.

Several studies have investigated the kinetic of $\mathrm{Pb}^{2+}$ removal by nZVI. Among a number of kinetic models, such as pseudo zero-order, pseudo first-order and pseudo second-order kinetic models, the pseudo first-order kinetic model was the most suitable which approves the best fit with the experimental data of $\mathrm{Pb}^{2+}$ removal compared to the rest of models [2]. As seen in Figure 5, the experimental data were well fitted to the pseudo first-order adsorption model with the high correlation coefficients. The parameters obtained by linear regression analysis were offered in Table 2. The results indicated a decrease in $K_{o b s}$ values from 0.04 to $0.01 \mathrm{~g} / \mathrm{mg} / \mathrm{min}$, when initial $\mathrm{Pb}^{2+}$ concentration increased from 100 to $800 \mathrm{mg} / \mathrm{L}$. The rate constant $K_{o b s}$ also increased by increasing S-nZVI dosage, and by approaching to a solution $\mathrm{pH}$ of 5 .

\section{e. Adsorption isotherms}

Experimental data were modeled using the well known adsorption models described by the Freundlich and Langmuir equations to study the ability of $\mathrm{Pb}^{2+}$ ions to adsorb on S-nZVI [22].

Based on the results of our experimental data fitting on these isotherms, in Table 3, nZVI has the good ability to reduce $\mathrm{Pb}^{2+}$ to $\mathrm{Pb}^{\circ}$ which can then be absorbed by the nZVI easily. Furthermore, data fitting by using the

Table 2 Pseudo first-order adsorption kinetics constants for $\mathrm{Pb}^{2+}$ removal by S-nZVI

\begin{tabular}{lllll}
\hline Parameters & $\mathbf{p H}: \mathbf{2 . 0}$ & $\mathbf{4 . 0}$ & $\mathbf{6 . 0}$ & $\mathbf{8 . 0}$ \\
\hline $\mathrm{K}_{\text {obs }}(1 / \mathrm{min})$ & -0.015 & -0.024 & -0.022 & -0.011 \\
$\mathrm{R}^{2}$ & 1.0 & 0.999 & 0.998 & 0.991
\end{tabular}

Fixed conditions: Initial $\mathrm{Pb}^{2+} 200 \mathrm{mg} / \mathrm{L}, \mathrm{S}-\mathrm{nZVI} 0.5 \mathrm{~g} / \mathrm{L}$

$\begin{array}{lllll}\text { Parameter } & \text { Initial } \mathbf{P b}^{2+}: \mathbf{1 0 0} \mathbf{~ m g / L} & \mathbf{2 0 0} & \mathbf{4 0 0} & \mathbf{8 0 0} \\ \mathrm{K}_{\text {obs }}(1 / \mathrm{min}) & -0.035 & -0.023 & -0.011 & -0.012 \\ \mathrm{R}^{2} & 0.999 & 0.999 & 0.999 & 0.997\end{array}$

Fixed conditions: S-nZVI $0.5 \mathrm{~g} / \mathrm{L}, \mathrm{pH} 4.0$,

$\begin{array}{llllll}\text { Parameter } & \text { S-nZVl:0.1 g/L } & \mathbf{0 . 2 5} & \mathbf{0 . 5} & \mathbf{1 . 0} & \mathbf{2 . 0} \\ \mathrm{K}_{\text {obs }}(1 / \mathrm{min}) & -0.012 & -0.020 & -0.024 & -0.033 & -0.026 \\ \mathrm{R}^{2} & 0.999 & 0.981 & 0.999 & 1.0 & 1.0\end{array}$

Fixed conditions: Initial $\mathrm{Pb}^{2+} 200 \mathrm{mg} / \mathrm{L}, \mathrm{pH} 4.0$, 
Table 3 Freundlich and Langmuir adsorption isotherms constants for $\mathrm{Pb}^{2+}$ removal by S-nZVI

\begin{tabular}{|c|c|c|c|c|c|c|}
\hline \multirow{2}{*}{$\begin{array}{l}\text { Parameters } \\
\text { Freundlich }\end{array}$} & \multicolumn{2}{|l|}{$\mathrm{pH}: 2.0$} & \multirow{2}{*}{$\frac{4.0}{-0.18}$} & \multirow{2}{*}{$\frac{6.0}{-0.21}$} & \multirow{2}{*}{$\frac{8.0}{-0.65}$} & \\
\hline & $1 / n$ & -0.51 & & & & \\
\hline & $K_{n}$ & 1996 & 571 & 629 & 3662 & \\
\hline \multirow[t]{2}{*}{ Langmuir } & $q_{\max }$ & 0.14 & 0.24 & 0.23 & 0.12 & \\
\hline & $\mathrm{K}_{\mathrm{l}}$ & 0.05 & 0.21 & 0.16 & 0.04 & \\
\hline \multicolumn{7}{|c|}{ Fixed conditions: Initial Pb 200 mg/L, S-nZVI 0.2 g/L } \\
\hline Parameter & & Initial $\mathrm{Pb}^{2+}: 100 \mathrm{mg} / \mathrm{L}$ & 200 & 400 & 800 & \\
\hline \multirow[t]{2}{*}{ Freundlich } & $1 / \mathrm{n}$ & -0.11 & -0.17 & -0.45 & -0.67 & \\
\hline & $K_{n}$ & 208 & 564 & 4615 & 43143 & \\
\hline \multirow[t]{2}{*}{ Langmuir } & $q_{\max }$ & 0.13 & 0.24 & 0.33 & 0.50 & \\
\hline & $\mathrm{K}_{1}$ & 0.71 & 0.20 & 0.03 & 0.01 & \\
\hline \multicolumn{7}{|c|}{ Fixed conditions: S-nZVI 0.2 g/L, pH 4.0, } \\
\hline Parameter & & S-nZVI:0.1 g/L & 0.25 & 0.5 & 1.0 & 2.0 \\
\hline \multirow[t]{2}{*}{ Freundlich } & $1 / n$ & -0.85 & -0.39 & -0.18 & -0.05 & -0.03 \\
\hline & $K_{n}$ & 43228 & 2335 & 571 & 204 & 38 \\
\hline \multirow[t]{2}{*}{ Langmuir } & $q_{\max }$ & 0.42 & 0.29 & 0.24 & 0.16 & 0.09 \\
\hline & $K_{1}$ & 0.02 & 0.06 & 0.21 & 1.43 & 2.83 \\
\hline \multicolumn{7}{|c|}{ Fixed conditions: Initial Pb²+ 200 mg/L, pH 4.0, } \\
\hline
\end{tabular}

Langmuir model give a better fit than by using the Freundlich model. This can be seen from the fitting data obtained that the correlation coefficient is higher for the Langmuir adsorption isotherm $(\sim 0.92)$ compared to that of the Freundlich model $(\sim 0.84)$.

\section{Continuous experiments \\ Transparent column}

\section{a. Effect of seepage velocity}

The results of seepage velocity tests are shown in Figure 4c. It was observed that a seepage velocity of $10 \mathrm{~m} / \mathrm{d}$ yielded the maximum removal rate. Furthermore, any variation, increasing or decreasing of this velocity, had a negative effect on the $\mathrm{Pb}^{2+}$ removal. Higher seepage velocities enhanced the mobility of nano particles through porous media and reduced the contact time and as a result, reduced the remediation efficiency.

\section{b. Effect of S-nZVI loading}

As shown in Figure 4e, when S-nZVI loading rose from 1 to $10 \mathrm{~g}$, the $\mathrm{Pb}^{2+}$ removal efficiency within 60 min increased from about $50 \%$ to $80 \%$. It is found out that when further amount of S-nZVI was injected, the $\mathrm{Pb}^{2+}$ removal has been improved.

\section{Bench-scale model}

The results of bench-scale experiments, illustrated in Figure 4f, indicated that the removal efficiency through sand materials were higher than glass beads. In addition, increasing seepage velocity had a decreasing effect on the $\mathrm{Pb}^{2+}$ remediation. Through bench-scale experiments, the best $\mathrm{Pb}^{2+}$ remediation efficiency was achieved, i.e. about $81 \%$. In $\mathrm{pH}$ of 4 , initial concentration of $200 \mathrm{mg} / \mathrm{L}$, and $15 \mathrm{~g} \mathrm{S-nZVI}$ injection, finally $31 \mathrm{~L}$ of treated water with $\mathrm{Pb}^{2+}$ concentration less than $20 \mathrm{mg} / \mathrm{L}$ was acquired. Therefore, it could be proposed that the capacity of $\mathrm{S}-\mathrm{nZVI}$ for in-situ lead removal is about $300 \mathrm{mg} \mathrm{Pb}^{2+} / \mathrm{g}$ S-nZVI.

\section{Conclusions}

Findings of this study indicated that starched nZVI has a good feasibility for in-situ lead remediation in contaminated water. Batch experiments proved that $\mathrm{pH}$ of solution was an important parameter while kinetics coefficients were directly related to $\mathrm{pH}$ with correlation coefficients $R^{2}>0.90$. In addition, increasing of S-nZVI dosage or decreasing $\mathrm{Pb}^{2+}$ initial concentration, both lead to enhancement in removal efficiency. It means that if mass-ratio between $\mathrm{nZVI}$ and $\mathrm{Pb}$ is kept constant, i.e. about 2.5, the removal rate would be invariable.

Transparent column experiments revealed that $\mathrm{Pb}^{2+}$ remediation also was mostly influenced by seepage velocity, grain size, and type of porous media. Bench-scale results confirmed the batch and transparent column outcomes. As a final point, because of the fast reaction kinetics and high $\mathrm{Pb}^{2+}$ removal capacity, S-nZVI has the fine potential to become an effective remedial agent in PRB for in-situ immobilization of lead in polluted groundwater resources. 


\section{Abbreviations}

nZVI: nano Zero Valent Iron particles; S-nZVI: Stabilized nano Zero Valent Iron particles; U.S.EPA: U.S. Environmental Protection Agency; PRB: Permeable Reactive Barriers; XRD: X-Ray powder Diffraction; SEM: Scanning Electron Microscopy; DLS: Dynamic light scattering.

\section{Competing interests}

The authors declare that they have no competing interests.

\section{Authors' contributions}

MR Fadaei Tehrani designed and developed the physical models, carried out the experiments and performed the analysis of results. As well as prepared the draft of manuscript. A Shamsai participated in the design of the study and performed the statistical analysis. M Vosughi conceived of the study, and participated in its design and coordination and helped to draft the manuscript. All authors read and approved the final manuscript. Furthermore, MR Fadaei Tehrani is the PHD candidate for Water Engineering doing his thesis under the supervisions of $A$ Shamsaei and $M$ Vosoughi in Civil Engineering Faculty of Sharif University of Technology.

\section{Acknowledgments}

This work was supported by the Institute of Biotechnology and Environment (IBE) in Sharif University of Technology, Tehran, Iran.

\section{Author details}

'Department of Civil Engineering, Sharif University of Technology, Tehran, Iran ${ }^{2}$ Institute of Biotechnology and Environment (IBE), Department of Chemical Engineering, Sharif University of Technology, Tehran, Iran.

Received: 19 June 2014 Accepted: 6 January 2015

Published online: 21 January 2015

\section{References}

1. Xu D, Tan X, Chen C, Wang X. Removal of Pb(II) from aqueous solution by oxidized multiwalled carbon nanotubes. Journal of Hazardous Materials. 2008;154(1-3):407-16.

2. Zhang X, Lin $\mathrm{S}$, Lu X-Q, Chen Z-I. Removal of Pb(II) from water using synthesized kaolin supported nanoscale zero-valent iron. Chemical Engineering Journal. 2010;163(3):243-8.

3. U.S.EPA: Drinking Water Contaminants, http://water.epa.gov/drink/ contaminants/index.cfm (accessed June 1, 2014). 2014.

4. Machida M, Mochimaru T, Tatsumoto H. Lead(II) adsorption onto the graphene layer of carbonaceous materials in aqueous solution. Carbon. 2006:44(13):2681-8.

5. Li L, Benson CH, Lawson EM. Modeling porosity reductions caused by mineral fouling in continuous-wall permeable reactive barriers. Journal of Contaminant Hydrology. 2006;83(1-2):89-121.

6. Cundy AB, Hopkinson L, Whitby RLD. Use of iron-based technologies in contaminated land and groundwater remediation: A review. Science of The Total Environment. 2008;400(1-3):42-51.

7. Rangsivek R, Jekel MR. Removal of dissolved metals by zero-valent iron (ZVI): Kinetics, equilibria, processes and implications for stormwater runoff treatment. Water Research. 2005:39(17):4153-63.

8. Yang GCC, Lee H-L. Chemical reduction of nitrate by nanosized iron: kinetics and pathways. Water Research. 2005;39(5):884-94.

9. Zhang X, Deng B, Guo J, Wang Y, Lan Y. Ligand-assisted degradation of carbon tetrachloride by microscale zero-valent iron. Journal of Environmental Management. 2011;92(4):1328-33.

10. Kim K-R, Lee B-T, Kim K-W. Arsenic stabilization in mine tailings using nano-sized magnetite and zero valent iron with the enhancement of mobility by surface coating. Journal of Geochemical Exploration. 2012:113:124-9.

11. Fagerlund F, Illangasekare TH, Phenrat T, Kim HJ, Lowry GV. PCE dissolution and simultaneous dechlorination by nanoscale zero-valent iron particles in a DNAPL source zone. Journal of Contaminant Hydrology. 2012;131(1-4):9-28.

12. Peng S, Wang C, Xie J, Sun S. Synthesis and stabilization of monodisperse Fe nanoparticles. Journal of the American Chemical Society. 2006:128(33):10676-7.

13. Lee C, Jee YK, Won IL, Nelson KL, Yoon J, Sedlak DL. Bactericidal effect of zero-valent iron nanoparticles on Escherichia coli. Environmental Science and Technology. 2008;42(13):4927-33.
14. Chris M, Kocur DMOA, Carroll Brent E. Impact of nZVI stability on mobility in porous media. Journal of Contaminant Hydrology. 2013;145:17-25.

15. Nataphan Sakulchaicharoen DMOC, Jose EH. Enhanced stability and dechlorination activity of pre-synthesis stabilized nanoscale FePd particles. Journal of contaminant hydrology. 2010;118:117-21.

16. He F, Zhao D. Preparation and characterization of a new class of starch-stabilized bimetallic nanoparticles for degradation of chlorinated hydrocarbons in water. Environ Sci Technol. 2005:39:3314-20.

17. Kanel SR, Neppolian B, Choi H, Yang JW. Heterogeneous catalytic oxidation of phenanthrene by hydrogen peroxide in soil slurry: Kinetics, mechanism, and implication. Soil and Sediment Contamination. 2003;12(1):101-17.

18. Yalei Zhang YS, Xuefei Z, Chaomeng D, Keller AA. A new insight on the core-shell structure of zerovalent ironnanoparticles and its application for $\mathrm{Pb}$ (II) sequestration. Journal of Hazardous Materials. 2013;263:685-93.

19. X.Q. Li WXZ. Sequestration of metal cations with zero valent iron nano particles- a study with high resolution $\mathrm{X}$-ray photoelectron spectroscopy (HR-XPS). J Phys Chem. 2007:111:6939-46.

20. Ponder SM, Darab JG, Mallouk TE. Remediation of $\mathrm{Cr}(\mathrm{VI})$ and $\mathrm{Pb}(\mathrm{II})$ aqueous solutions using nanoscale zero-valent iron. Environ Sci Technol. 2000;34:2564-9.

21. Yunfei Xi MM, Ravendra N. Reduction and adsorption of $\mathrm{Pb} 2+$ in aqueous solution by nano-zero-valent iron-A SEM, TEM and XPS study. Materials Research Bulletin. 2010;45:1361-7.

22. Freundlich HMF. Adsorption in solids. Zeitschrif $t$ fuer Physikalisch-Chemie. Stoechiometrie Verwandtschaftslehre. 1906;57:385-470.

\section{Submit your next manuscript to BioMed Central and take full advantage of:}

- Convenient online submission

- Thorough peer review

- No space constraints or color figure charges

- Immediate publication on acceptance

- Inclusion in PubMed, CAS, Scopus and Google Scholar

- Research which is freely available for redistribution 